\title{
Qualidade da Intervenção Pedagógica na Perspetiva do Professor e do Aluno.
}

\section{Calidad de la intervención pedagógica en el aula, en la perspectiva del profesorado y del alumnado.}

\section{Elsa Maria Ribeiro da Silva}

Universidade de Coimbra Faculdade de Ciências do Desporto e Educação Física:

Coimbra, Coimbra, Portugal

Ribeiro da Silva. E.M. (2017). Calidad de la intervención pedagógica en el aula, en la perspectiva del profesorado y del alumnado. Revista Prácticum, Vol 2(2) 18-31. ISSN 2530-4550 


\section{Resumo}

Este estudo tem por objetivo investigar a existência de convergência entre professores estagiários, a desempenharem a função de docente numa escola, e os respetivos alunos, na forma de perceber e interpretar as práticas educativas que os primeiros utilizam e os segundos vivenciam, acreditando que a qualidade do processo de ensinoaprendizagem em muito depende daquela convergência. Aplicámos dois questionários construídos em "espelho", a 12 professores estagiários em Educação Física e respetivos alunos do ensino secundário (288), tendo os resultados apontado para a existência de algumas convergências mas de muitas divergências. Convergências, de uma forma geral, na ordem de importância que atribuem às dimensões, categorias e indicadores resultantes da análise dos dados, e divergências na valoração de cada uma delas, sendo evidente a tendência dos professores estagiários sobrevalorizarem a qualidade das suas práticas relativamente à opinião dos respetivos alunos. Estes resultados permitem que os estagiários reforcem os pontos positivos da sua intervenção pedagógica e se consciencializem dos negativos, levando-os à busca de soluções.

\section{Resumen}

Este estudio tiene como objetivo investigar la existencia de convergencia entre profesores en prácticas, desempeñando la función de docente en una escuela, y su alumnado. De este modo, estudiaremos la forma de entender e interpretar las prácticas educativas que este profesorado utiliza y sus alumnos vivencian, creyendo que la calidad del proceso de enseñanza-

-aprendizaje depende, en gran escala, de dicha convergencia. Hemos aplicado dos encuestas construidas en "espejo", a 12 profesores de Educación Física en prácticas y sus respectivos alumnos de bachillerato (288), apuntando los resultados para la existencia de algunas convergencias, pero muchas más divergencias. Convergencias, de forma general, en el orden de importancia que atribuyen a las dimensiones, categorías e indicadores resultantes de la análisis de los datos, y divergencias en la valoración de cada una de ellas, siendo evidente la tendencia que el profesorado en prácticas sobrevalore la calidad de sus prácticas relativamente a la opinión de sus respectivos alumnos. Estos resultados permiten que el profesorado en prácticas refuerce los puntos positivos de su intervención pedagógica y se conciencie de los negativos, llevándoles a la búsqueda de soluciones.

\section{Palavras-chave:}

Convergências, Intervenção pedagógica, Alunos, Professores, Estágio Pedagógico

\section{Palabras clave:}

Convergencia, Intervención pedagógica, Alumnos, Profesores, Practicum 


\section{Introdução}

A docência é uma profissão que se aprende desde que se entra na escola pela observação de comportamentos dos nossos professores, (Formosinho, 2001), pelo que, e apesar de cumprido todo um trajeto de formação inicial e por vezes contínuo, muitos se mantêm agarrados a princípios e práticas pelas quais passaram enquanto alunos e que adotaram como professores, sem que em algum momento do seu percurso profissional as tenham refletido ou questionado.

Poucas são as profissões em que os indivíduos que a estão a iniciar já tiveram um contacto tão íntimo, intenso e duradouro com a sua realidade. Quando o professor dá os "primeiros passos" na sua profissão já conta com um passado vivido na escola como aluno que lhe proporcionou o contacto com diferentes tipos de atuação e múltiplos métodos de ensino da parte dos seus professores. Esta realidade não é, no entanto, garantia de ausência de dificuldades, já que aquela "superfamiliarização" com o ensino, segundo Siedentop e Tannehill (2000) (citado por Queirós 2014:71), ao darlhe a ideia de que domina tudo o que respeita às práticas, métodos e conteúdos de ensino, cria-lhe a falsa perceção de que sabe tudo sobre a profissão.

Num tempo em que a exigência com a profissão docente é cada vez maior, num desafio constante à sua credibilidade, identidade e profissionalidade, é fundamental que se aposte na qualidade da formação dos professores, apetrechando-os com instrumentos teóricos, práticos e técnicos que Ihes permitam desempenhar uma prática que responda à escola atual, cada vez mais dinâmica e multicultural. Para tal é necessária uma formação inicial pensada e vivida neste sentido.

A capacidade de diagnosticar problemas, de refletir e investigar sobre eles, são competências fundamentais para os professores, que devem ser desenvolvidas durante a formação inicial, de forma a contrariar a tendência de ancoragem das suas decisões, atitudes e práticas nos conhecimentos adquiridos enquanto alunos.

Neste estudo, realizado com estagiários do Mestrado em Ensino de Educação Física nos Ensinos Básico e Secundário, partimos da ideia de que a convergência de entendimentos, ao nível das decisões, atitudes e práticas, entre os professores e os alunos, é um fator fundamental para o sucesso das (e nas) aprendizagens dos alunos e do ensino do professor.

Tal como McCaughtry \& al (2008), pensamos que a relação entre professor e aluno depende, fundamentalmente, do clima estabelecido pelo professor na aula, da relação empática com os seus alunos, da sua capacidade de ouvir, refletir e discutir o nível de compreensão daqueles e da criação das pontes entre o seu conhecimento e o deles, o que, não acontecendo, gera frequentemente representações nos professores de que os seus alunos são incapazes de aprender.

É neste sentido que Rosado e Mesquita (2009) defendem que o ambiente de aprendizagem resulta da convergência entre duas agendas, a dos professores e a dos alunos, contendo estas as suas expectativas, os seus valores e as suas conceções acerca do ensino, implicando esta convergência um processo de negociação entre professores e alunos para que seja possível a concretização dos objetivos de ambos.

No que respeita aos alunos, as suas agendas contêm, ainda, intenções de divertimento, socialização, aprovação, minimização de esforço, afastamento de problemas, não aborrecimento, entre outras, pelo que, os programas de ação dos professores não são aceites passivamente, procurando os alunos alterar as tarefas de modo a ajustá-las às suas agendas pessoais, gerando-se aqui conflitos e processos de negociação entre alunos e professores com o objetivo de melhor gerir os ambientes de aprendizagem. 
Já em 1990, Abreu e Masetto se tinham aproximado desta ideia, quando afirmaram que era o modo de agir do professor em sala de aula, mais do que as suas características de personalidade que contribuíam para uma adequada aprendizagem dos alunos, a qual se fundamenta numa determinada conceção do papel do professor, que por sua vez reflete valores e padrões da sociedade. Ideia que mais tarde Vlachopoulos y Biddlle (1996) (citado por Murcia, Galindo e Gimeno, 2009) vieram reforçar afirmando que as intervenções do docente na aula jogam um papel importante como veículo de valores, atitudes e comportamentos, constituindo uma parte significativa do comportamento social e psicológico dos estudantes.

Sabemos que a aprendizagem não surge espontaneamente associada ao prazer, sendo quase sempre encarada como obrigação (Armour, 2015), e que o processo de aprendizagem se torna mais interessante quando o aluno se sente competente pelas atitudes e métodos de motivação em sala de aula implementados pelo professor.

Importa, pois, que os métodos utilizados pelo professor se constituam num processo estratégico de ensino-aprendizagem baseado em decisões conscientes, com o objetivo de desencadear no aluno a apetência necessária para decidir fundadamente sobre os atos a realizar (Font, C. 2007).

Como Birzea (1982:9) afirmava, os eventuais insucessos escolares deveriam ser explicados mais pela ineficácia dos métodos educativos, que pela incapacidade dos alunos. Nesta linha, acreditamos que quando o professor não consegue lograr os seus objetivos de ensino, não é, normalmente, por falta de interesse, investimento ou conhecimentos, mas por não estar a intervir de acordo com as especificidades, necessidades e/ou motivações dos alunos.

Designando-o de trajetórias de ensino (professor) e de aprendizagem (aluno) divergentes, é a esta conjuntura que atribuímos muito do insucesso ou dos entraves ao sucesso de que inúmeras vezes os professores se lamentam, não percebendo, ou não querendo assumir, estar neles tanto a causa como a solução do problema.

É aqui que uma formação inicial pensada e vivida para e na aprendizagem se torna fundamental, em que tanto os alunos dos estagiários como estes, eles próprios também alunos, ocupem o centro do processo de ensino-aprendizagem, numa perspetiva que se pretende construtivista e favorável à promoção de ambientes positivos de aprendizagem.

Tal como Zabalza (2016), consideramos o Estágio Pedagógico um momento e uma componente essencial do processo de formação dos nossos estudantes, pelo que se torna fundamental que nos preocupemos com a qualidade e pertinência das experiências que nele vivem e com as aprendizagens dali resultantes, razão pela qual decidimos realizar este estudo com estagiários, portanto, com mestrandos no seu último ano de formação inicial.

O Estágio Pedagógico (unidade curricular pertencente aos $3 .^{\circ}$ e $4 .^{\circ}$ semestres dos mestrados em ensino, no ensino universitário), tem por função final a profissionalização de novos docentes através de um processo de prática profissional autónoma, embora orientada por dois professores (escola e faculdade), com a duração de um ano letivo e no qual os alunos desempenham funções em tudo idênticas às da docência numa escola. E seu objetivo favorecer a integração e mobilização dos conhecimentos adquiridos ao longo dos ciclos anteriores de estudos, através da prática de ensino supervisionada em contexto real, de forma a habilitar os futuros professores com competências adequadas ao exercício da profissão. 


\section{Metodologia}

Este estudo, no âmbito da formação inicial em Educação Física, teve por base uma metodologia mista, qualitativa-quantitativa, onde foram conciliadas técnicas de estatística descritiva no tratamento das questões fechadas com a análise do conteúdo na questão aberta.

\section{Participantes}

Os participantes neste estudo surgem organizados em dois subgrupos: o primeiro composto por 12 estagiários, 4 do sexo feminino e 8 do masculino, com uma média de idades de 23 anos e sem tempo de serviço docente, os quais, daqui em diante, passaremos a designar por "professores" (e não por aluno estagiário), para evitarmos confusão com os alunos do ensino secundário, constituintes do outro subgrupo da amostra.

Este segundo subgrupo é composto pela totalidade dos alunos das turmas dos "professores", num total de 288 indivíduos, dos quais 160 a frequentar o $10 .{ }^{\circ}$ ano de escolaridade obrigatória e 128 a frequentar o $11 .{ }^{\circ}$ ano. Estes alunos apresentavam, quer na sua totalidade quer por sexo, uma média de idades de 17 anos, sendo 48\% (138) do sexo masculino e $52 \%$ (150) do feminino.

\section{Instrumentos e Procedimentos}

Aplicámos dois questionários construídos em "espelho", os quais designámos por Questionário da Avaliação da Qualidade Pedagógica no Ensino Secundário para o Professor e Questionário da Avaliação da Qualidade Pedagógica no Ensino Secundário para o Aluno. Apesar de seguirem a mesma matriz e objetivos das questões, tivemos a preocupação de adaptar o questionário destinado aos alunos, tanto em relação à terminologia, ajustando-a ao seu nível cognitivo, como à escala das respostas, as quais decidimos fazer coincidir com os quatro níveis qualitativos de avaliação normalmente utilizados no ensino secundário: "Não satisfaz", "Satisfaz", "Satisfaz Bem" e "Satisfaz Muito Bem" Os questionários apresentavam-se estruturados em três partes: a primeira constituída por questões fechadas, de caracterização pessoal dos participantes; a segunda, em escala tipo Likert, composta por um conjunto de 30 indicadores/afirmações, em relação aos quais os participantes deveriam manifestar o grau de concordância; a terceira constituída por uma questão aberta que solicitava que fossem referidos os aspetos que cada individuo considerava mais importantes para a melhoria das aulas de Educação Física. Ainda relativamente à segunda parte, os 30 indicadores que a constituíam relacionavam-se com as formas de atuar do professor e apresentavam-se agrupados em duas grandes dimensões: Intervenção Pedagógica e Relação Pedagógica, a primeira categorizada em Planeamento/Organização, Ensino e Avaliação e a segunda em Atitude Pedagógica e Apoio ao Estudo.

Para uma primeira validação da escala do tipo Likert, procedemos à aplicação prévia de ambos os questionários a populações idênticas às posteriormente inquiridas (estagiários a lecionarem a turmas do $30^{\circ}$ ciclo e alunos do ensino secundário de turmas não pertencentes ao núcleo de estágio), processo que nos permitiu a eliminação dos indicadores que se revelaram não discriminadores da opinião. 
Optámos por limitar a aplicação dos questionários, exclusivamente, ao ensino secundário, pelo facto de considerarmos que aqueles não se ajustavam linguística e terminologicamente a alunos mais jovens.

Os questionários foram aplicados separadamente aos dois subgrupos da amostra, tendo a aplicação aos "professores" sido feita pelo respetivo professor cooperante e aos alunos por um estagiário, que não o "professor" da turma.

De modo a garantirmos a confidencialidade e anonimato das respostas, os alunos e "professores" que se voluntariaram a participar no estudo foram previamente instruídos sobre a importância do não registo de qualquer informação que tornasse possível a sua identificação, assim como da possibilidade de desistirem a qualquer momento do preenchimento. Foilhes, ainda, assegurado que os resultados seriam usados apenas para fins académicos e pelo grupo de investigadores implicados na pesquisa.

\section{Tratamento dos Dados}

No tratamento dos dados foi usado o SPSS, versão 23.0, para o tratamento estatístico das respostas às questões fechadas, correspondentes às duas primeiras partes dos questionários, tendo-se optado por fazer corresponder um valor quantitativo a cada um dos níveis da escala de respostas dos alunos, de modo a permitir-nos o tratamento estatístico: não satisfaz - 1; satisfaz - 2; satisfaz bem - 3 e satisfaz muito bem - 4 .

Para a análise do conteúdo das respostas à questão aberta usámos um processo de categorização por critério semântico (Bardin, 2009), com dimensões previamente definidas e coincidentes com as grandes questões colocadas, mas sem categorias constituídas à partida, tendo-se seguido um processo de discussão entre pares, tanto para a validação daquelas categorias, como, posteriormente, para a codificação dos respetivos segmentos de registo.

\section{Resultados}

\section{Apresentação dos resultados relativos aos 30 indicadores}

Como já referimos, esta questão, em escala de Likert, era composta por 30 indicadores/afirmações, divididos em duas grandes dimensões: Relação pedagógica e Intervenção pedagógica.

Quanto a estas, os "professores" consideraram ter desempenhos sensivelmente idênticos nas duas dimensões, apesar de haver uma ligeira valoração da dimensão Relação Pedagógica com 3,40, em relação aos 3,39 da dimensão Intervenção Pedagógica. Já os alunos, apesar de manterem a mesma ordem de valoração, atribuem-Ihes valores significativamente inferiores e distintos, 3,26 e 3,15 respetivamente, considerando que os seus "professores" apresentam uma capacidade relacional superior ao restante desempenho. 
Tabela 1. Categorização dos resultados dos 30 indicadores/indicadores

\begin{tabular}{|c|c|c|c|c|c|}
\hline \multicolumn{6}{|c|}{ 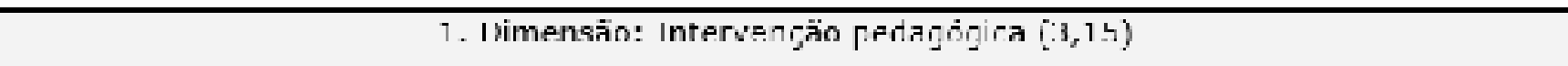 } \\
\hline \multirow[t]{2}{*}{ I:At=goria } & \multirow[t]{2}{*}{ 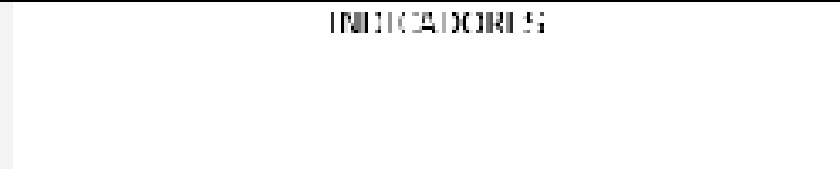 } & \multicolumn{2}{|c|}{ 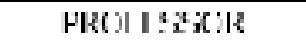 } & \multicolumn{2}{|c|}{ Al IINIC1:: } \\
\hline & & $\begin{array}{l}\text { Mèr a por } \\
\text { ind cader }\end{array}$ & $\begin{array}{l}\text { Mé-ia } \\
\text { categ }\end{array}$ & $\begin{array}{l}\text { Méria por } \\
\text { indicedor }\end{array}$ & $\begin{array}{l}\text { Mé-ia } \\
\text { zateg }\end{array}$ \\
\hline \multirow{4}{*}{$\begin{array}{l}\text { 1.I } \\
\text { Planejillento } \\
\text { Or } \\
\text { Orani catão }\end{array}$} & 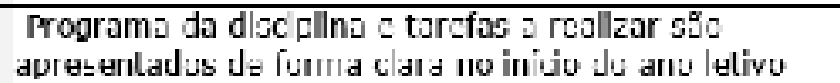 & 3.17 & 3,50 & 3,12 & 3,30 \\
\hline & As *ılas iniriam-q e p terminam no horärin & $2,-41$ & & 3,14 & \\
\hline & I xiste azsiduidade do(a) profesmr(a) à.s नulas & 4,1111 & & $3, / 7$ & \\
\hline & $\begin{array}{l}\text { A disiplina eatai nganizarta de modo a farilitar } \\
\text { suecrso nas aprondlzagens }\end{array}$ & 2,191 & & 3,16 & \\
\hline \multirow[t]{11}{*}{$\begin{array}{l}1.2 \\
\text { Ensino }\end{array}$} & 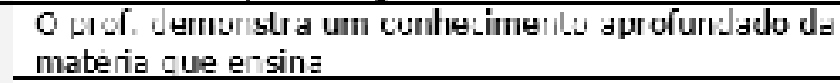 & 3,00 & 3,19 & 3,30 & 3,12 \\
\hline & 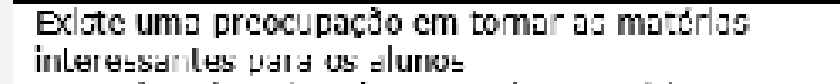 & 3,50 & & 3,13 & \\
\hline & 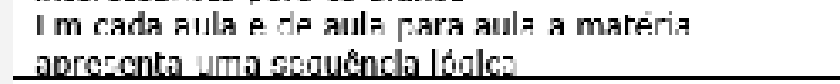 & $\therefore, r$ & & $3,2 \%$ & \\
\hline & $\begin{array}{l}\text { O frot. Frocura ser original e inovador no modo } \\
\text { cmmen=ine }\end{array}$ & 3,33 & & 2,88 & \\
\hline & 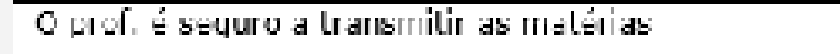 & 3,33 & & 3,23 & \\
\hline & 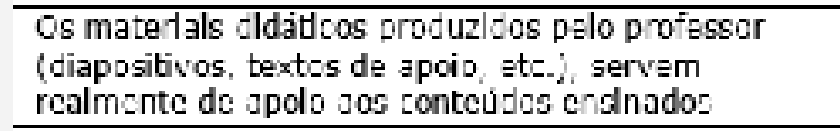 & 3,00 & & 3,13 & \\
\hline & $\begin{array}{l}\text { O frot. estimula a intervençäo do sluno e a } \\
\text { expressàn das sluas ideia= }\end{array}$ & 3,17 & & 3,01 & \\
\hline & 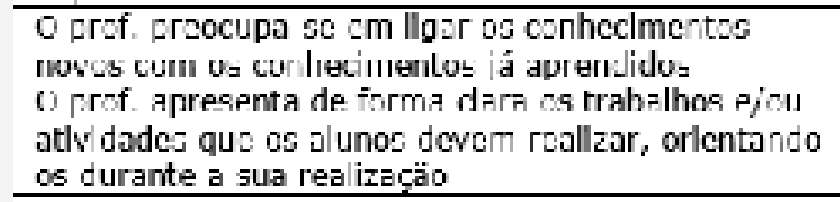 & 3,00 & & 3,19 & \\
\hline & 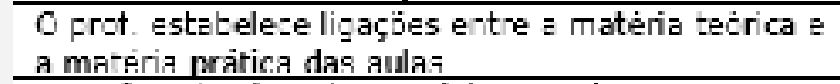 & 3,17 & & 3,26 & \\
\hline & 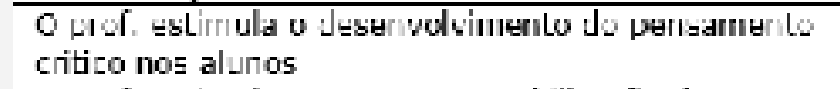 & 2,67 & & 2,75 & \\
\hline & () rorof estimula a Futnrresponsahiliz=cän dos & 11 & & 3,01 & \\
\hline \multirow[t]{4}{*}{$\begin{array}{l}1.3 \\
\text { Avaliaçäo }\end{array}$} & $\begin{array}{l}\text { O plovesu aval ialive apresella-be claro y } \\
\text { inecuivo:o }\end{array}$ & 3,50 & 3,50 & 3,05 & 3,05 \\
\hline & 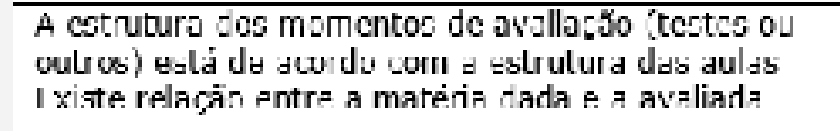 & $\begin{array}{l}3.67 \\
i, f l\end{array}$ & & 3,22 & \\
\hline & 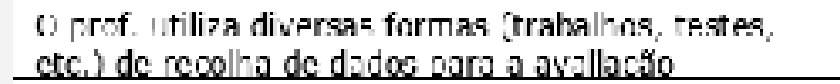 & $1,-11$ & & 2,97 & \\
\hline & 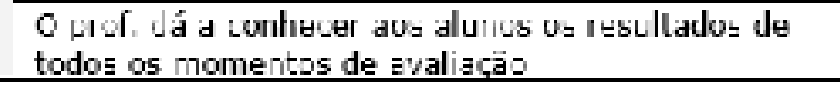 & 3,17 & & 2,69 & \\
\hline
\end{tabular}


2. Dimensão: Relação Pedagógica $(3,26)$

\begin{tabular}{|c|c|c|c|c|c|}
\hline \multirow{5}{*}{$\begin{array}{l}2.1 \\
\text { Atitude } \\
\text { pedagógica }\end{array}$} & O prof. trata os alunos com respeito & 3,83 & \multirow[t]{5}{*}{3,43} & 3,60 & \multirow[t]{5}{*}{3,32} \\
\hline & Existe relação positiva entre o professor e os alunos & 3,50 & & 3,50 & \\
\hline & O prof. interessa-se pelas aprendizagens dos alunos & 3,67 & & 3,43 & \\
\hline & O prof. preocupa-se em tratar os alunos igualmente & 3,00 & & 3,27 & \\
\hline & $\begin{array}{l}0 \text { prof. mostra-se aberto a ideias diferentes dos } \\
\text { alunos sobre as matérias }\end{array}$ & 3,17 & & 2,81 & \\
\hline \multirow{4}{*}{$\begin{array}{l}2.2 \\
\text { Apoio ao } \\
\text { estudo }\end{array}$} & $\begin{array}{l}\text { O prof. mostra disponibilidade para atender os } \\
\text { alunos no final das aulas }\end{array}$ & 3,67 & \multirow[t]{4}{*}{3,38} & 3,45 & \multirow[t]{4}{*}{3,21} \\
\hline & O prof. mostra disponibilidade para ajudar os alunos & 3,83 & & 3,51 & \\
\hline & $\begin{array}{l}\text { O prof. cria motivação para os alunos trabalharem } \\
\text { autonomamente para além das aulas }\end{array}$ & 3,00 & & 2,91 & \\
\hline & O prof. apoia o estudo autónomo dos alunos & 3,00 & & 2,97 & \\
\hline
\end{tabular}

Analisando por categorias (tabela 1 ) temos que, em relação ao Planeamento e Organização, a totalidade dos "professores" considerou-se totalmente assíduo às aulas $(4,00)$, e a grande maioria considerou que as aulas se iniciavam e terminavam a horas $(3,50)$, enquanto os alunos, concordando com os seus professores, atribuíram, no entanto, valores sensivelmente menores: 3,77 e 3,14, respetivamente.

Ainda dentro da mesma categoria, os "professores" consideraram como o menos conseguido a apresentação da disciplina e do tipo de trabalhos a realizar no início do ano lectivo, $(3,17)$, tal como os seus alunos, mas estes com uma valoração ainda menor $(3,12)$.

Já na categoria Ensino, temos como indicadores mais valorados pelos "professores" a sequência lógica entre as aulas e matérias $(3,67)$ e a preocupação em tornar as matérias interessantes para os alunos $(3,50)$, ambos no nível de muito bom, sendo o indicador menos valorado a estimulação do desenvolvimento do pensamento crítico dos alunos, $(2,67)$.

Para os alunos, os indicadores mais importantes foram, a demonstração, por parte do professor, de um domínio aprofundado da matéria que ensina, $(3,30)$, logo seguido da sequência lógica entre as aulas e matérias e da apresentação de forma clara dos trabalhos e/ou atividades a realizar pelos alunos, ambos com 3,27.

Tal como os "professores", também os alunos consideraram ser o menos conseguido da parte daqueles a estimulação do desenvolvimento do pensamento critico dos alunos, sendo, no entanto, menos rigorosos na avaliação, $(2,75)$.

$\mathrm{Na}$ categoria Avaliação, temos como aspetos mais conseguidos para os "professores" o facto dos momentos de avaliação estarem de acordo com a estrutura das aulas e a existência de relação entre a matéria avaliada e a matéria dada, ambos no nível de muito bom $(3,67)$, enquanto os seus alunos, para além de Ihes atribuírem apenas o nível de bom, ainda consideraram valorar mais o primeiro $(3,39)$, relativamente ao segundo indicador $(3,22)$.

Como menos conseguido nesta categoria, temos, na opinião dos "professores", o dar a conhecer aos alunos os resultados de todos os momentos de avaliação $(3,17)$, coincidindo com a opinião dos alunos, estes, no entanto, muito mais críticos $(2,69)$.

Passando para a dimensão Relação Pedagógica e no que respeita à categoria Atitude Pedagógica, os "professores" consideraram a sua prática de nível muito bom quanto ao tratarem os alunos com respeito $(3,83)$, logo seguida pelo seu interesse pelas aprendizagens dos alunos" $(3,67)$, tendo os seus alunos concordado, embora com menor incidência, com o primeiro indicador $(3,60)$, mas relegando para terceiro lugar o interesse pelas suas aprendizagens $(3,43)$, atribuindo mais importância à existência de uma relação positiva entre professor e alunos $(3,50)$. 
No que respeita à categoria de Apoio ao Estudo, os "professores" referiram como seus pontos fortes a disponibilidade para ajudarem os alunos durante as aulas $(3,83)$, logo seguida da disponibilidade para atenderem os alunos no final das aulas, $(3,67)$, atribuindo-Ihes um nível de muito bom. A mesma opinião é manifestada pelos alunos, mas com valores expressivamente mais baixos: 3,51 e 3,45, respetivamente.

Como aspetos menos conseguidos reconhecidos pelos "professores" temos "o professor cria motivação para os alunos trabalharem autonomamente para além das aulas" e "o professor apoia o estudo autónomo dos alunos", ambos com 3,00, enquanto os alunos, para além de atribuírem valores menores a estas atitudes, ainda consideram ser a motivação para trabalharem autonomamente para além das aulas $(2,91)$, a menos conseguida pelo professor.

\section{Apresentação dos resultados relativos à questão aberta}

Esta questão constituía a terceira parte do questionário e inquiria sobre os aspetos que os participantes consideravam mais prementes de serem alterados com vista à melhoria das aulas de Educação Física. A análise do conteúdo das respostas dos "professores" levou-nos à constituição de quatro categorias (tabela 2) e a dos alunos a quatro categorias e quinze subcategorias (tabela 3 ).

\section{a) "Professores":}

Como se pode verificar pela tabela 2, os aspetos que os "professores" entenderam como mais importantes de serem alterados referem-se ao âmbito das Decisões Organizativas da Escola ( $38,46 \%)$, com o objetivo de aumentar e/ou rentabilizar o tempo de aula, sendo os indicadores mais referidos a necessidade de aumentar o número de aulas por matéria e a redução do número de alunos por turma, ambos com 15,38\%.

A par desta temos uma segunda categoria com os mesmos valores percentuais e que se refere ao reconhecimento dos inquiridos sobre as suas Necessidades de Formação $(38,46 \%)$, especificamente sobre a necessidade de aumentar a sua segurança na lecionação em algumas das matérias e de aumentar o conhecimento próprio sobre os conteúdos, ambos com 15,38\%.

Tabela 2 - Aspetos a melhorar nas aulas de EF - "professores"

\begin{tabular}{|c|c|c|c|c|}
\hline CATEGORIAS & INDICADORES & $\begin{array}{l}\% \text { do indicador } \\
\text { na categ. } \\
\text { (a) }\end{array}$ & $\begin{array}{l}\% \text { do indicador } \\
\text { no total } \\
\text { (b) }\end{array}$ & $\begin{array}{l}\% \text { por } \\
\text { categ. } \\
\text { (c) }\end{array}$ \\
\hline \multirow{3}{*}{$\begin{array}{l}1 . \\
\text { Decisões } \\
\text { organizativas }\end{array}$} & $\begin{array}{l}\text { Aumentar o número de aulas de } \\
\text { cada modalidade. }\end{array}$ & $\begin{array}{c}4 \\
40 \% \\
\end{array}$ & $15,38 \%$ & \multirow{3}{*}{$\begin{array}{c}10 \\
38,46 \%\end{array}$} \\
\hline & Aumentar o número de aulas. & $\begin{array}{c}2 \\
20 \%\end{array}$ & $7,69 \%$ & \\
\hline & $\begin{array}{l}\text { Reduzir o número de alunos por } \\
\text { turma. }\end{array}$ & $\begin{array}{c}4 \\
40 \% \\
\end{array}$ & $15,38 \%$ & \\
\hline
\end{tabular}




\begin{tabular}{|c|c|c|c|c|}
\hline \multirow{3}{*}{$\begin{array}{l}2 . \\
\text { Necessidades } \\
\text { de formação }\end{array}$} & $\begin{array}{l}\text { Aumentar o conhecimento próprio } \\
\text { sobre os conteúdos. }\end{array}$ & $\begin{array}{c}4 \\
40 \%\end{array}$ & $15,38 \%$ & \multirow{3}{*}{$\begin{array}{c}10 \\
38,46 \%\end{array}$} \\
\hline & $\begin{array}{l}\text { Aumentar a segurança de } \\
\text { lecionação de certas matérias. }\end{array}$ & $\begin{array}{c}4 \\
40 \% \\
\end{array}$ & $15,38 \%$ & \\
\hline & $\begin{array}{l}\text { Rentabilizar o tempo disponível para } \\
\text { a prática da aula. }\end{array}$ & $\begin{array}{c}2 \\
20 \% \\
\end{array}$ & $7,69 \%$ & \\
\hline \multirow{2}{*}{$\begin{array}{l}3 . \\
\text { Característica } \\
\text { s dos alunos }\end{array}$} & $\begin{array}{l}\text { Alunos com pouca maturidade para } \\
\text { o ano que frequentam. }\end{array}$ & $\begin{array}{c}2 \\
50 \% \\
\end{array}$ & $7,69 \%$ & \multirow{2}{*}{$\begin{array}{l}4 \\
15,38 \%\end{array}$} \\
\hline & Alunos sem noção de jogo. & $\begin{array}{c}2 \\
50 \% \\
\end{array}$ & $7,69 \%$ & \\
\hline $\begin{array}{l}\text { 4. Estrutura } \\
\text { do processo } \\
\text { de avaliacão } \\
\end{array}$ & $\begin{array}{l}\text { Peso desequilibrado de cada período } \\
\text { na avaliação final. }\end{array}$ & $\begin{array}{c}2 \\
100 \%\end{array}$ & $7,69 \%$ & $\begin{array}{c}2 \\
7,69 \%\end{array}$ \\
\hline Total registos & & & & 26 \\
\hline
\end{tabular}

Legenda:

(a) valor absoluto e relativo do indicador em relação ao total da categoria;

(b) $\%$ do indicador em relação ao total de indicadores;

(c) \% da categoria em relação ao total de registos.

\section{b) Alunos:}

No que respeita aos alunos, os resultados foram categorizados em Planeamento, Avaliação, Relação Pedagógica e Estratégias de Intervenção Pedagógica (tabela 3). No conjunto destas quatro categorias o maior número de registos foi atribuído ao Planeamento, $(37,79 \%)$ e, dentro desta, à subcategoria Inovação nas matérias e tarefas, $(39,58 \%)$, sendo a necessidade de inovação dos exercícios $(27,08 \%)$ o indicador mais valorado.

Ainda dentro da categoria Planeamento e na mesma linha dos resultados anteriores, surge valorada de forma expressiva a subcategoria de necessidade de Inovação na estrutura das aulas (33,33\%), com a importância do estagiário ter mais autonomia do orientador para inovar a aula e a necessidade de inovar as aulas (14,58\%), como indicadores mais referidos.

Quanto à categoria Avaliação (31,49\%), apesar de ser a segunda mais valorada, apresenta, dentro da subcategoria Insuficiência informacional o indicador mais valorado de toda a categorização, sendo ele a necessidade de o professor dever dar mais informação sobre os resultados da avaliação (52,50\%).

Passando para as Estratégias de Intervenção Pedagógica (19,68\%), é de referir que sendo-Ihe apenas atribuído o terceiro lugar nas categorias, apresenta a subcategoria mais valorada de toda esta categorização e que respeita às Estratégias pedagógicas de organização, cujos indicadores o professor não deve separar alunos e alunas $(32,00 \%)$ e o professor deve fazer os grupos de alunos equilibrados em relação ao nível de desempenho $(28,00 \%)$, obtiveram, no seu conjunto, $60 \%$ das escolhas na totalidade da categoria.

Por fim, no que respeita à categoria Relação Pedagógica $(11,02 \%)$, apesar de ser a menos valorada pelos alunos, há, no entanto, dois aspetos a destacar: a subcategoria Professor mais próximo dos alunos, com metade dos registos da categoria, e o indicador que se refere à necessidade do professor tratar todos os alunos de forma igual, pertencente à subcategoria Equidade no tratamento dos alunos, o qual obteve $28,57 \%$ das escolhas em relação ao total da categoria. 
Tabela 3 - Aspetos a melhorar nas aulas de EF - alunos

\begin{tabular}{|c|c|c|c|}
\hline CATEGORIAS & SUBCATECORIAS & INDICADORES & $\begin{array}{l}\text { \% do } \\
\text { [ndlc. } \\
\text { ח Catcg. }\end{array}$ \\
\hline \multirow{10}{*}{$\begin{array}{l}\text { Plantusingnilu } \\
\begin{array}{c}37,79 \% \\
(18)\end{array}\end{array}$} & \multirow{3}{*}{$\begin{array}{l}\text { d) Furmas de dbor dar maléríds } \\
\text { e conleúdos } \\
\qquad 12,50 \% \text { (5) }\end{array}$} & $\begin{array}{l}\text { Mudalidadu= abudadas cum d } \\
\text { mesma interlaidade }\end{array}$ & $\begin{array}{l}4,16 \% \\
\text { (2) }\end{array}$ \\
\hline & & $\begin{array}{l}\text { Terminar uma matérla ontes de } \\
\text { so Inlclar a segulnte }\end{array}$ & $\begin{array}{l}1,16 \% \\
\text { (2) }\end{array}$ \\
\hline & & 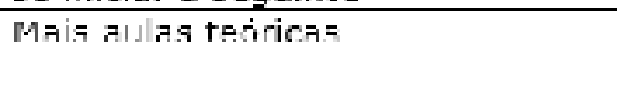 & $\begin{array}{l}4,1 t^{+11} \\
\text { (y) }\end{array}$ \\
\hline & \multirow{2}{*}{$\begin{array}{l}\text { hj Innvaçäo nas matẹrias e } \\
\text { contelidns } \\
\qquad 14,64: 14)\end{array}$} & $\begin{array}{l}\text { Diversitiraçäo/ nä̀ repetigāo das } \\
\text { modalidades }\end{array}$ & $\begin{array}{l}12, \mathrm{rn} \% \% \\
(\mathrm{r})\end{array}$ \\
\hline & & Inovar os exercicios & $\begin{array}{c}27,10 \% \\
(1 \Xi) \\
\end{array}$ \\
\hline & \multirow{3}{*}{$\begin{array}{l}\text { c) Inovaçān na estrutura ta:= } \\
\text { aulas } \\
\qquad 13,1,140(1 \mathrm{~h})\end{array}$} & Innvar as aulas & $\begin{array}{l}\text { 14, hl:'su } \\
(1)\end{array}$ \\
\hline & & Aumentar dinämica das aulas & $\begin{array}{c}4,16 \% \\
(2)\end{array}$ \\
\hline & & 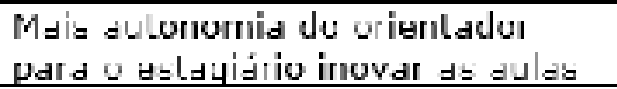 & $\begin{array}{c}14,58 \% \\
(7)\end{array}$ \\
\hline & \multirow{2}{*}{$\begin{array}{l}\text { d) Ajusldirientos no } \\
\text { aquecimento } \\
\qquad 14,58 \%(7)\end{array}$} & Aquecimento mais inuvadur & $\begin{array}{c}6,25 \% \\
(3)\end{array}$ \\
\hline & & $\begin{array}{l}\text { Aquecimerilo mais jjuslado d̀ } \\
\text { modalidade }\end{array}$ & $\begin{array}{c}8,33 \% \\
(4) \\
\end{array}$ \\
\hline \multirow{7}{*}{$\begin{array}{c}\text { Avaliagan } \\
\left.: 11,49^{\prime}\right) \\
(40)\end{array}$} & 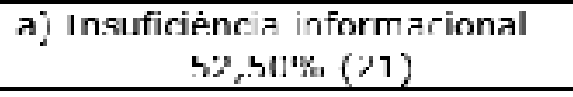 & $\begin{array}{l}\text { Prnfessor deve dar mais } \\
\text { informagan anhre os resultadns }\end{array}$ & 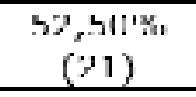 \\
\hline & $\begin{array}{r}\text { b] Prucessu irifurmadiunal } \\
10,00 \%(4)\end{array}$ & $\begin{array}{l}\text { Prufessur deve inlurllld us } \\
\text { dlunus em plivede }\end{array}$ & $\begin{array}{c}10,00 \% \\
(4)\end{array}$ \\
\hline & $\begin{array}{c}\text { c) Aval|a,̧a Ind|v|dual|zada } \\
5,00 \% \text { (2) }\end{array}$ & $\begin{array}{l}\text { Excrciclos de avallaçăo devem } \\
\text { ser dlferentes de aluno para } \\
\text { aluno }\end{array}$ & $\begin{array}{l}5,00 \% \\
\text { (2) }\end{array}$ \\
\hline & $\begin{array}{l}\text { d) Número de testes de } \\
\text { avallaças }\end{array}$ & $\begin{array}{l}\text { Malor número de testes o } \\
\text { trabalhos }\end{array}$ & $\begin{array}{l}10,00 \% \\
(1)\end{array}$ \\
\hline & $25,00 \%(10)$ & PMenor nimero de teates e=rritns & 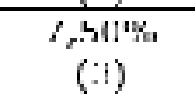 \\
\hline & & Eliminaçäo dos testes & $\begin{array}{c}7,50 \% \\
(3)\end{array}$ \\
\hline & 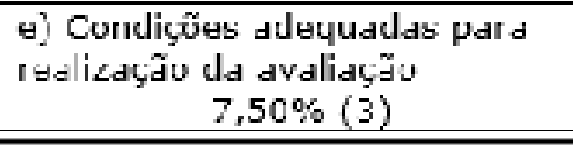 & 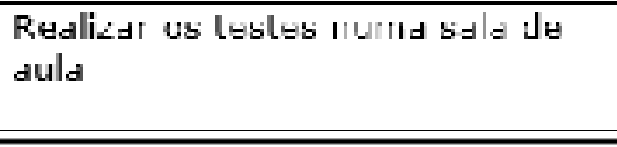 & $\begin{array}{l}7,50 \% \\
(3)\end{array}$ \\
\hline \multirow{6}{*}{$\begin{array}{l}4 . \\
\text { Estratégias de } \\
\text { Intervenção } \\
\text { Pedagógica }\end{array}$} & \multirow{2}{*}{$\begin{array}{l}\text { a)Estratégias pedagógicas de } \\
\text { ensino } \\
\qquad 28,00 \%(7)\end{array}$} & $\begin{array}{l}\text { Professor deve focar-se mais nos } \\
\text { alunos com dificuldades }\end{array}$ & $\begin{array}{c}12,00 \% \\
(3)\end{array}$ \\
\hline & & $\begin{array}{l}\text { Professor deve dar mais tempo } \\
\text { de jogo para cimentar as } \\
\text { aprendizagens. }\end{array}$ & $\begin{array}{c}16,00 \% \\
(4)\end{array}$ \\
\hline & \multirow{2}{*}{$\begin{array}{l}\text { b) Estratégias pedagógicas de } \\
\text { organização } \\
\qquad 60,00 \%(15)\end{array}$} & $\begin{array}{l}\text { Professor deve fazer grupos de } \\
\text { nível de desempenho equilibrado }\end{array}$ & $\begin{array}{c}28,00 \% \\
(7)\end{array}$ \\
\hline & & $\begin{array}{l}\text { Professor não deve separar } \\
\text { rapazes e raparigas }\end{array}$ & $\begin{array}{l}32,00 \% \\
(8)\end{array}$ \\
\hline & $\begin{array}{l}\text { c) Disciplina } \\
12,00 \%(3)\end{array}$ & $\begin{array}{l}\text { Professor deve ter maior controlo } \\
\text { disciplinar dos alunos }\end{array}$ & $\begin{array}{c}12,00 \% \\
(3)\end{array}$ \\
\hline & & Total registos & 127 \\
\hline
\end{tabular}




\section{Discussão}

Após esta apresentação, alguns dos resultados merecem ser destacados pela sua relevância para a qualidade do ensino, por contribuírem para a melhoria da intervenção pedagógica dos formandos e por irem ao encontro da questão que levantámos no inicio deste estudo.

Assim sendo, podemos verificar que é a nível da Avaliação que se regista a maior divergência entre a perceção dos "professores" e dos seus alunos, com uma diferença de 0,45 entre as médias das diferenças de todos os indicadores da categoria, sempre mais valorada pelos primeiros. Esta divergência chega a atingir uma diferença de 0,59 no indicador respeitante ao uso de diversas formas de recolha de dados para avaliação, com os alunos a considerarem-no escassamente satisfaz e os "professores" muito perto do valor máximo. Isto significa que, enquanto os "professores" consideram estar a agir corretamente, diversificando as formas e instrumentos de recolha de dados para a avaliação, os seus alunos consideram haver aqui uma significativa necessidade de melhoria.

O mesmo se passa relativamente à informação dada pelo "professor" sobre os resultados dos diversos momentos de avaliação $(\neq 0,48)$, com aqueles a considerá-la muito boa e os alunos a registarem a existência de uma significativa insuficiência informacional.

Também quanto à clareza do processo avaliativo e à estrutura dos instrumentos de avaliação de acordo com a estrutura das aulas, as diferenças de valoração são expressivas $(\neq 0,45)$, revelando-nos que, enquanto os professores consideram as suas propostas naqueles âmbitos muito boas, os alunos pensam necessitar de mais informação relativamente ao seu processo avaliativo, assim como maior coerência entre os modelos e formas de lecionação dos conteúdos e os modelos e formas de os avaliar.

Em suma, dos cinco indicadores relativos à dimensão Avaliação, quatro apresentam uma diferença superior a 0,45, sendo, de longe, a dimensão em que as divergências entre as perceções de "professores" e de alunos são maiores e todas elas significativamente mais valoradas pelos "professores".

Estes resultados conduzem-nos a Furlan (2006), que num estudo idêntico concluiu terem, professores e alunos, um entendimento idêntico da importância da Avaliação, divergindo, no entanto, na forma como a representam.

Quanto às outras categorias, as divergências não são tão significativas; no entanto, temos a destacar algumas diferenças que nos parecem merecer maior reflexão.

Dentro destas temos, na categoria Ensino, três indicadores com uma diferença média de valoração de cerca de 0,40 entre alunos e "professores", com os primeiros a pronunciarem-se a favor de uma maior necessidade do "professor" tornar as matérias mais interessantes, de ser original e inovador e das aulas apresentarem uma sequência mais lógica de conteúdos.

De destacar que, apesar disto, os alunos consideram que os "professores" têm um bom domínio das matérias que ensinam, facto que não é tão reconhecido pelos próprios docentes.

Este apelo à originalidade e inovação não é inédito e vem na linha de vários autores cujos trabalhos apontam para uma constante repetição de matérias e conteúdos ao longo da escolaridade, levando Blázquez (2013:42) a referir os alunos como os eternos principiantes. 
Relativamente à relação pedagógica, de novo surgem divergências expressivas de valoração, considerando os "professores" que se mostram mais abertos a ideias diferentes dos alunos e mais disponíveis para os ajudar do que os seus alunos pensam que realmente acontece.

No que respeita à análise dos fatores considerados decisivos para a melhoria da qualidade das aulas de Educação Física, os "professores" associam aquele incremento maioritariamente a fatores não dependentes de si (62\%), tais como a forma como o ensino está organizado (rotatividade dos espaços de aula, tempos de aula reduzidos, número de alunos por turma demasiado elevado), as características dos alunos e a estrutura do processo de avaliação. Apesar disto e, embora atribuindo-Ihe um valor significativamente mais reduzido (38\%), não deixam de reconhecer que a melhoria da sua formação académica teria influência positiva na qualidade das aulas.

Por seu lado, os alunos insistem em apontar principalmente para a necessidade de inovação, quer das matérias, quer das formas de as ensinar, e ainda para a necessidade de serem mais esclarecidos no seu processo de avaliação.

Concluindo, podemos notar que coexistem pontos de convergência e divergência na forma de perceber as práticas pedagógicas, já que, por um lado, foi frequente "professores" e alunos ordenarem da mesma forma dimensões, categorias e indicadores, mas por outro, atribuíram-Ihe importâncias diferentes, sendo evidente haver uma tendência dos "professores" em valorizarem mais as suas práticas quando comparamos com a opinião dos seus alunos. Os mesmos resultados foram encontrados por Iberico, Valle \& Pease (2016), justificando-os pela tendência dos professores em sobrevalorizarem a qualidade da sua intervenção.

As maiores divergências ficaram patentes nas respostas à questão aberta, onde os estagiários revelaram preocupações com a sua formação e a sua segurança na lecionação, dois aspetos intimamente relacionados, considerando que os devem incrementar, apesar de já os reputarem de bom nível.

A par destas apresentam também preocupações de âmbito organizativo, como o aumento do número de aulas por unidade didática e a redução do número de alunos por turma.

Quanto aos alunos do ensino secundário, as suas perceções relativamente às práticas do professor vão para a necessidade de inovação das aulas, das matérias e das tarefas; da informação que necessita de ter do seu desempenho nos momentos da avaliação; nas estratégias pedagógicas de organização que o professor utiliza, nomeadamente na necessidade de sentirem mais proximidade e justiça na forma do professor intervir, referindo dever ser tratados de forma igual pelo docente.

Estes resultados alicerçam a nossa opinião de que a "superfamiliarização" com o ensino de Siedentop e Tannehill (2000), (citado por Queirós 2014:71), tem induzido os nossos "professores", não tanto a crerem que sabem tudo sobre a profissão, já que se revelam preocupados com a sua formação, mas antes a empurrá-los para a replicação das mesmas matérias, modelos e metodologias que experimentaram enquanto alunos do ensino básico e secundário, realidade que pensamos estar diretamente relacionada com a perceção de falta de inovação dos seus alunos. 


\section{Bibliografia}

Armour, K. (2015). The case for 'Physical Activity Education' through the life-course, Journal of Sport Pedagogy and Research. 1(3), 4-5. Obtido a 20-1-2017 em: https://www.ipg.pt/scpd/files/JSPR_2_1.pdf

Bardin, L. (2009). Análise de conteúdo. Coimbra: Edições 70, 95-102.

Birzea, C. (1982) La Pedagogía del Éxito. Barcelona: Gedisa, P9.

Blázquez, D. (2013) Diez competencias docentes para ser mejor profesor de Educación Física - La gestión didáctica de la clase (pp 28 e 42). Barcelona: INDE. Bogdan, R. e Biklen, S. (1994). Investigação Qualitativa em Educação. Porto: Porto Editora.

Font, C. (2007), Estratégias de Ensino e Aprendizagem, col. práticas pedagógicas, Porto, ASA editores, pp 10.

Formosinho (2001), A Formação prática de professores. Da prática docente na instituição de formação à prática pedagógica nas escolas, in Bártolo Paiva Campos (org.). Formação Profissional dos Professores no Ensino Superior, Porto: Porto Editora, pp 46-64.

Furlan, M. I. (2006). Avaliação da aprendizagem escolar: convergências e divergências entre os atores do processo de uma escola pública de ensino médio. Tese de mestrado. Universidade Oeste Paulista. S. Paulo-Brasil

Iberico, Valle \& Pease (2016), Students and Techers' Perceptions of the Most valued Teaching Actions, Athens Journal of Education, may 2016, pp 105-119.

McCaughtry, N., Tischler, A. \& Flory, S. (2008), The Ecology of the Gym: Reconceptualized and Extended, Quest, 60, pp 268-289.

Murcia, Galindo, Gimeno (2009), Revista Educación 355. Mayo-Agosto 2011, pp 381-403. Acedido em 29/08/2017. http://www.espacoacademico.com.br/052/52pc_silva.htm

Pestana, M.H. \& Gajeiro J.N. (2003), Análise de dados para as Ciências Sociais: A Complementaridade do SPSS (4a edição), Lisboa: Edições Sílabo

Queirós, P. (2014), Da formação à profissão: O lugar do estágio profissional, in O estágio profissional na (re)construção da identidade profissional em Educação Física, coordenação de Batista, P., Graça, A. \& Queirós, P., Ed. UPorto, p71.

Rosado A. e Ferreira V. (2009), Promoção de ambientes positivos de aprendizagem, in Rosado A. e Mesquita I., (org.) Pedagogia do Desporto, pp 185-206, Lisboa, Edições FMH.

Zabalza, M. (2016).El Practicum y las prácticas externas en la formación universitaria, Revista Prácticum (editorial), Vol. 1, No. 1, pp 1-23. Acedido em 2/09/2017 http://revistapracticum.com/index.php/iop/article/view/15 